\title{
Proportional lumbar spine inter-vertebral motion patterns: a comparison of patients with chronic, non-specific low back pain and healthy controls
}

\author{
Fiona E. Mellor • Peter W. Thomas • \\ Paul Thompson • Alan C. Breen
}

Received: 5 October 2013/Revised: 10 March 2014/Accepted: 13 March 2014/Published online: 28 March 2014

(C) The Author(s) 2014. This article is published with open access at Springerlink.com

\begin{abstract}
Introduction Identifying biomechanical subgroups in chronic, non-specific low back pain (CNSLBP) populations from inter-vertebral displacements has proven elusive. Quantitative fluoroscopy (QF) has excellent repeatability and provides continuous standardised inter-vertebral kinematic data from fluoroscopic sequences allowing assessment of mid-range motion. The aim of this study was to determine whether proportional continuous IV rotational patterns were different in patients and controls. A secondary aim was to update the repeatability of QF measurement of range of motion (RoM) for inter-vertebral (IV) rotation.

Methods and Materials Fluoroscopic sequences were recorded of passive, recumbent coronal and sagittal motion, which was controlled for range and velocity. Segments L2-5 in 40 primary care CNSLBP patients and 40 matched controls were compared. Patients also completed the von Korff Chronic Pain Grade and Roland and Morris Disability Questionnaire. Sequences were processed using automated image tracking algorithms to extract continuous inter-
\end{abstract}

Electronic supplementary material The online version of this article (doi:10.1007/s00586-014-3273-3) contains supplementary material, which is available to authorized users.

F. E. Mellor · A. C. Breen ( $\square)$

Institute for Musculoskeletal Research and Clinical

Implementation, Anglo-European College of Chiropractic,

Parkwood Road, Bournemouth BH5 2DF, UK

e-mail: imrci.abreen@aecc.ac.uk

F. E. Mellor · P. Thompson

School of Health and Social Care, Bournemouth University, Bournemouth BH1 3LT, UK

P. W. Thomas

Clinical Research Unit, School of Health and Social Care,

Bournemouth University, Bournemouth BH1 3LT, UK vertebral rotation data. These were converted to continuous proportional ranges of rotation (PR). The continuous proportional range variances were calculated for each direction and combined to produce a single variable representing their fluctuation (CPRV). Inter- and intra-rater repeatability were also calculated for the maximum IV-RoM measurements obtained during controlled trunk motion to provide an updated indication of the reliability and agreement of QF for measuring spine kinematics.

Results CPRV was significantly higher in patients (0.011 vs. 0.008, Mann-Whitney two-sided $p=0.008$ ), implying a mechanical subgroup. Receiver operating characteristic curve analysis found its sensitivity and specificity to be $0.78 \%(60-90)$ and $0.55 \%$ (37-73), respectively (area under the curve 0.672 ). CPRV was not correlated with pain severity or disability. The repeatability of maximum inter-vertebral range was excellent, but range was only significantly greater in patients at L4-5 in right side bending $(p=0.03)$.

Conclusion The variation in proportional motion between lumbar vertebrae during passive recumbent trunk motion was greater in patients with CNSLBP than in matched healthy controls, indicating that biomechanical factors in passive structures play a part.

Keywords Spine kinematics - Subgroups - Movement disorders $\cdot$ Repeatability $\cdot$ Reliability $\cdot$ Agreement

\section{Background}

Low back pain makes a large contribution to the burden of disability worldwide, but its pathophysiology in most sufferers is poorly understood [1]. Despite sub-classification into serious spinal pathology, nerve root pain and nonspecific low back pain, the majority of cases are in the 
latter category and defy classification [2]. The theoretical framework provided by the bio-psychosocial model [3] has so far focussed mainly on psychosocial components, but individual psychosocial factors are not strong determinants of who will experience first-time low back pain $[4,5]$, chronic disabling low back pain in the future [6], or poor outcomes from recent episodes [7].

There is a need to further study the biomechanics of the lumbar spine, but information on the mid-range is not possible from flexion extension radiographs (functional radiography) despite their widespread use in research and clinical practice [8]. Additionally, it is difficult to discriminate between normal and abnormal motion in living people from these due to large differences in techniques and large biological variation [9]. Fluoroscopy can reveal both end and mid-range motion and marked improvements are seen in precision when the measurements are automated [10].

Spinal motion underlies the rationales for many commonly used therapies, however motion-based classification systems seem to be largely a matter of professional preference. Objective evidence of patient subgroups remains elusive [11] and there remains a requirement to define the best methods of measuring spinal motion [12].

Some recent cross-sectional comparisons of chronic, non-specific low back pain (CNSLBP) patients and controls using flexion-extension radiographs have reported good inter-rater reliability and have shown restricted sagittal rotation to be associated with recurrent or chronic low back pain [13]. However, these have been undertaken during uncontrolled, weight-bearing maximum trunk bending and are subject to high intra subject variation [14].

Other two-dimensional motion studies have expressed inter-vertebral rotation as the proportional contributions of individual inter-vertebral levels to total lumbar or cervical spine motion $[15,16]$ allowing comparisons without contamination from inter-subject variation. Proportional motion, for example in three adjacent segments, is expressed as

Contribution $L x=\frac{L x}{L x+L y+L z}$

( $L x, L y, L z$ : contributions to motion of adjacent segments.)

Abbott et al. [15] found that when expressed as a proportion of the sum of the ranges of the segments under consideration, the prevalence of lumbar motion segments in patients exceeding reference intervals derived from healthy controls became highly significant, more so than when only comparing maximum rotation. However, this was an end of range study, which does not provide sufficient information to assess for functional instability, defined as "the loss of the spine's ability to maintain its pattern of displacement under normal physiological loads" [17].

Quantitative fluoroscopy (QF) provides continuous inter-vertebral motion data and reduces intra subject variations as participants are guided to the same range at the same velocity [18]. QF allows kinematic measurements to be extracted from weight-bearing (active) and nonweight-bearing (passive) motion in both the coronal and sagittal planes [19-22] and kinematic outputs have included inter-vertebral rotations and translations [15], attainment rates [20] and centres of rotation [19, 23]. However, no QF study has used continuous proportional motion data for the comparison of patients and controls.

This study aims to determine whether continuous proportional motion patterns from passive, uni-planar lumbar spine motion can distinguish between patients with CNSLBP and healthy controls. A new way of measuring this is proposed, using the variances of the proportional ranges between levels [proportional range variance (PRV)] for each direction, and their sums [combined proportional range variance (CPRV)] (Fig. 1). The study also sought to update the repeatability of maximum rotational range values to reflect the decreasing errors associated with improvements in the QF technique [18].

\section{Objectives}

The objectives of this study were

1. To determine whether the variations in proportional ranges across motion sequences are significantly different between patients and controls.

2. To calculate the sensitivity and specificity of the PRV and CPRV values to discriminate patients from controls.

3. To update the observer agreement and reliability (SEM and ICC) of maximum IV-rotational measurements in passive recumbent motion measured with $\mathrm{QF}$.

4. To determine whether there are relationships between CPRV and pain or disability.

\section{Methods}

This was a cross-sectional, prospective observational study of passive controlled motion in the lumbar spine.

\section{Participants}

A convenience sample of 40 patients aged between 21 and 50 years presenting to primary care (either chiropractic or outpatient physiotherapy) for CNSLBP was recruited. The age range was kept above 20 and below 51 in an attempt to minimise the influence of age on motion Wong et al. [22]. Forty pain-free healthy volunteers matched for gender, age and body-mass index (BMI) formed a control group. The eligibility criteria for the study are shown in Table 1. 

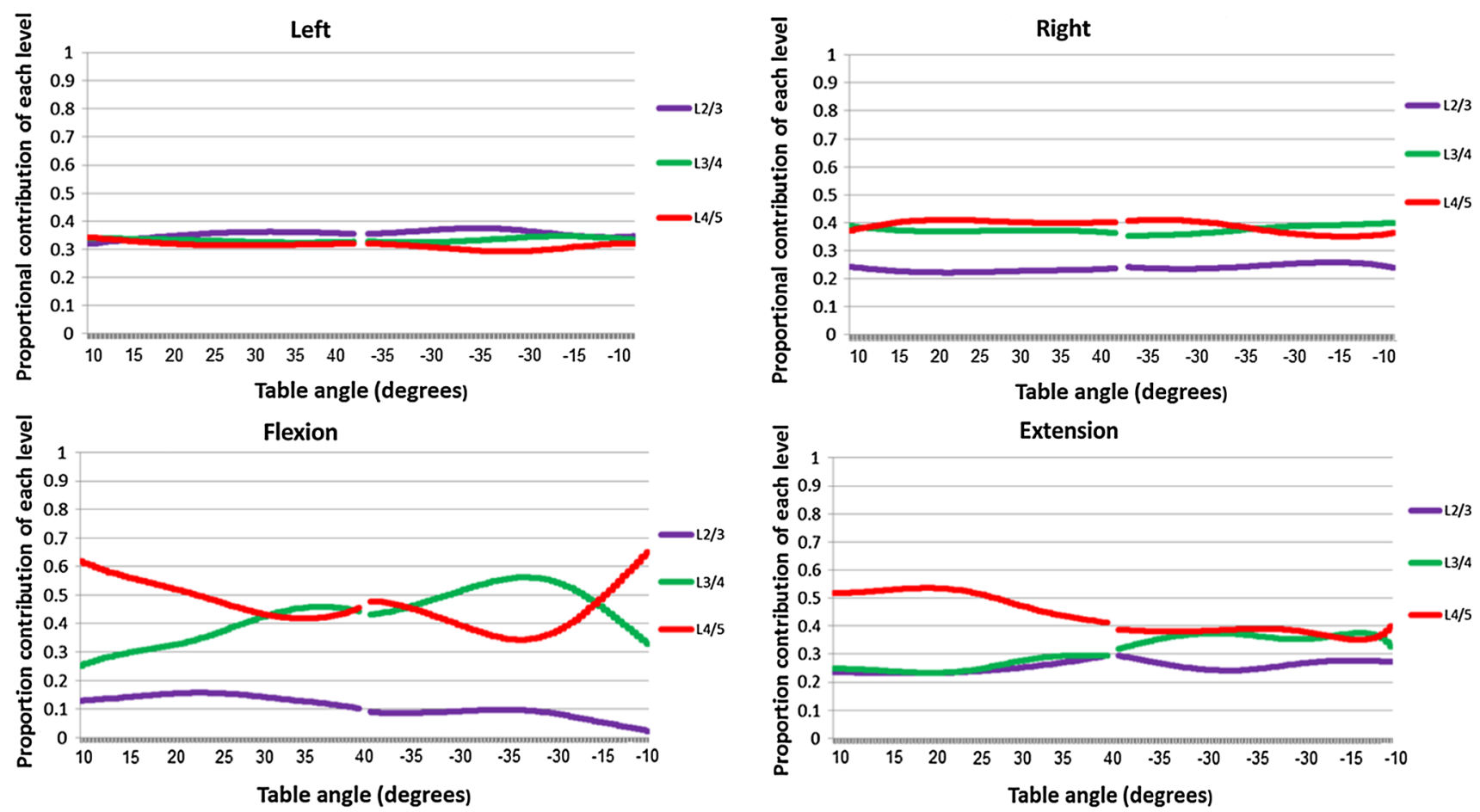

Fig. 1 Examples of mid-range patterns of L2-5 proportional inter-vertebral rotation in left, right, flexion and extension motion

Table 1 Inclusion and exclusion criteria

\begin{tabular}{ll}
\hline All participants & Inclusion criteria: male and female. Age 21-51 years (Wong et al. [22]). Able to understand written information. Willing to \\
participate and able to freely give informed consent. Menstruation within last 28 days, or evidence of contraceptive use, or \\
sterility (for females only). Consent to GP being informed of inclusion in study. Able to tolerate $80^{\circ}$ of side-bending and \\
flexion-extension passive trunk motion \\
Exclusion criteria: pregnancy, mental illness, depression, poor understanding of English. Recent abdominal or pelvic surgery. \\
Previous mid-lumbar spinal surgery. Body mass index (BMI) $>31$. Medical radiation exposure in the past 2 years with a \\
dose of greater than $8 \mathrm{mSv}$ (defined as CT scan of chest, abdomen or pelvis or interventional procedures under radiological \\
control, i.e. angiography). Current involvement in any other research study. Hyper-mobility syndrome \\
Inclusion criteria: back pain of $>3 \mathrm{~m}$ duration. Von Korff chronic pain grade II or higher (Von Korff et al. [25]) aggravated or \\
relieved by movement or position. Positive prone lumbar spinous pressure test between L2 and L5. Score of 4 or greater on \\
the Roland Morris Disability Questionnaire (Roland and Morris [24]) \\
Exclusion criteria: pathology such as fracture, infection, neoplasm. Spinal stenosis. Spondyolisthesis. Radicular pain. \\
Litigation or compensation pending \\
Healthy \\
Inclusion criteria: no history of low back pain that ceased normal activity for 1 day in previous year. Negative prone lumbar \\
spinous pressure test L2-L5
\end{tabular}

Patients completed the Roland and Morris Disability Questionnaire (RMDQ) [24] and the von Korff Chronic Pain Grade [25]. Ethical approval was gained from the UK National Research Ethics Service (Southampton A 09/HO5O2/99) and informed consent was taken by the principal investigator (FM).

\section{Sample size}

A sensitivity of $80 \%$ and a specificity of $90 \%$ might be thought of as desirable for identifying biomechanical abnormalities in patients and controls. An observed sensitivity of $80 \%$ with a sample size of 40 would have a lower
$95 \%$ confidence limit of $65 \%$ and a specificity of $90 \%$ would have a lower $95 \%$ confidence limit of $77 \%$. Further, based on the assumption from previous pilot studies that the prevalence of mechanical abnormality in patients and controls might be around 60 and $20 \%$, respectively, 40 per group would give the study over $90 \%$ power to detect a difference of this magnitude using a $5 \%$ level of significance.

\section{Image acquisition and analysis}

The study utilised recumbent passive motion as described in other studies $[10,26]$. The table moved the lower trunk to a range of $40^{\circ}$ and back over a period of approximately 
$12 \mathrm{~s}$ in each direction (left, right, flexion and extension). Only L2-5 levels were imaged to minimise image registration failures at $\mathrm{S} 1$ due to superimposition of the iliac crests.

Participants first lay supine on a bespoke motion table (Atlas Clinical Ltd.) with L3/4 at its fulcrum and the lumbar lordosis flattened by a cushion supporting the knees. Left and right sequences were undertaken separately. Participants then turned onto a left lateral decubitus position and the procedure was repeated for flexion and extension (see Online Resources videos 1 \& 2).

A mobile Siemens Arcadis Avantic (VC10A) image intensifier was positioned with its central ray aligned through L3-4 and fluoroscopy at $15 \mathrm{~Hz}$ was synchronised with the table motion. Exposure factors were determined by the automatic exposure device (AED) and ranged from 60 to $120 \mathrm{kVp} / 26.6$ to $63.1 \mathrm{~mA}$. Dose was recorded with a dose area product meter and converted to $\mathrm{mSv}$ using Monte Carlo simulation software (PCXMC) using the latest tissue weighting factors (ICRP 2007) and an assumed constant field size of $30 \mathrm{~cm} \times 30 \mathrm{~cm}$.

The fluoroscopic sequences were transferred to a desktop computer and Image J (v 1.47 for Windows OS) was used to separate the individual images from the digital sequences. The images underwent user defined edge enhancement, after which templates were manually placed five times around each vertebral body (L2-L5) in the first image. Two trained observers undertook this process on a subset of 10 randomly selected participants to allow calculation of the repeatability of this process. Bespoke software written in Matlab (V R2007b, The Mathworks Inc.) used a cross-correlation method to obtain automated frame to frame image tracking of the vertebral bodies in subsequent images. Co-ordinates were placed on the vertebral body corners in the first image, linked to the tracking templates and used to register the vertebrae in twodimensional space in each frame. Tracking was verified for quality assurance by viewing all sequences and repeating any tracking that failed (see Online Resource video 3), Averaged inter-vertebral angles from the five trackings throughout the motion were calculated using the Distortion Compensated Roentgen Analysis method [27]. Previous studies using this method found that translation and up to $10^{\circ}$ of out of plane rotation did not materially influence the accuracy of inter-vertebral angle measurement [26]. All patients were recruited and their data acquired, anonymised and analysed by FM.

\section{Repeatability}

Table motion was controlled for range. The maximum inter-vertebral range of motion (RoM) for L2-3, L3-4 and L4-5 achieved at any point throughout the $40^{\circ}$ range of the table was calculated as the highest $y$-value per inter-vertebral level (Fig. 2). Observers manually identified the maximum and minimum points of the continuous intervertebral motion pattern. Both intra- and inter-observer repeatability were assessed using intraclass correlations $\left(\mathrm{ICC}_{\text {agreement }} 2,1\right)$ [28] and the standard error of measurement $\left(\mathrm{SEM}_{\text {agreement }}\right)$ [29].

\section{Statistical analysis}

Continuous rotations were converted to proportional contributions for each inter-vertebral level $(n=3)$ per direction $(n=4)$ (Fig. 1) (see Online Resource 4 for further examples of continuous proportional motion per level and direction). Low overall $\mathrm{L} 2-5$ rotation at the initial and final $10^{\circ}$ of table motion meant that proportional values were only calculated for the middle $80 \%$.

To obtain a numerical expression of the fluctuations of the proportional patterns, the range between the maximum and minimum contribution at each frame was calculated (regardless of which inter-vertebral level contributed to the
Fig. 2 Determination of maximum rotational IV-RoM three adjacent levels in extension. Patterns of continuous raw inter-vertebral rotation range ( $Y$-axis) against motion table angle ( $X$-axis) at three adjacent levels in extension showing maximum ranges. Note that the maxima occur at different points in the motion

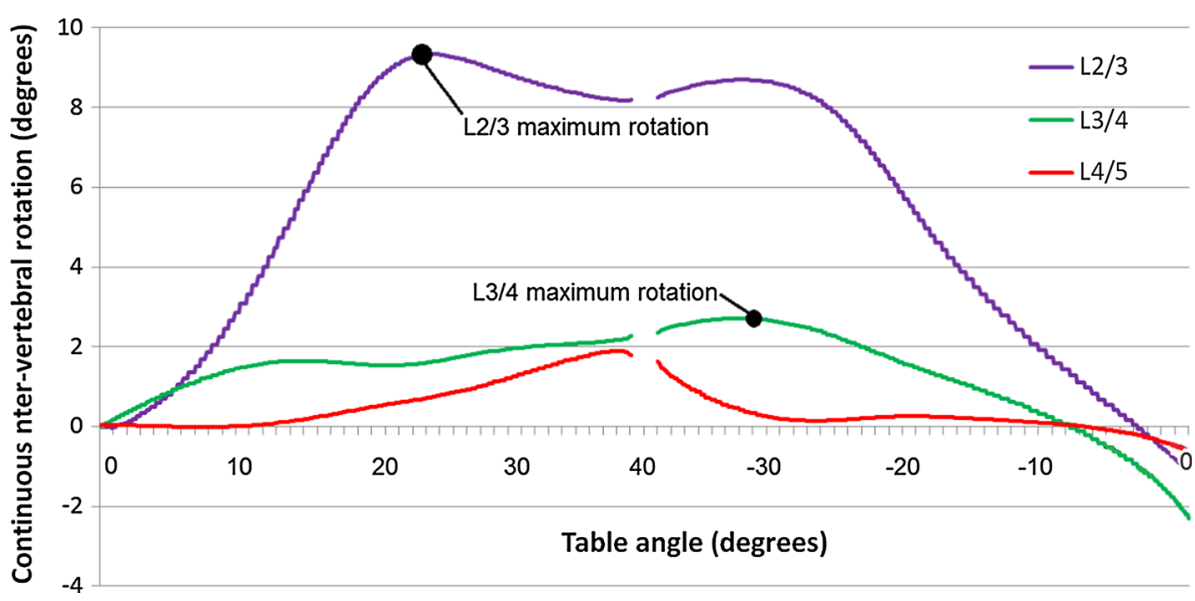




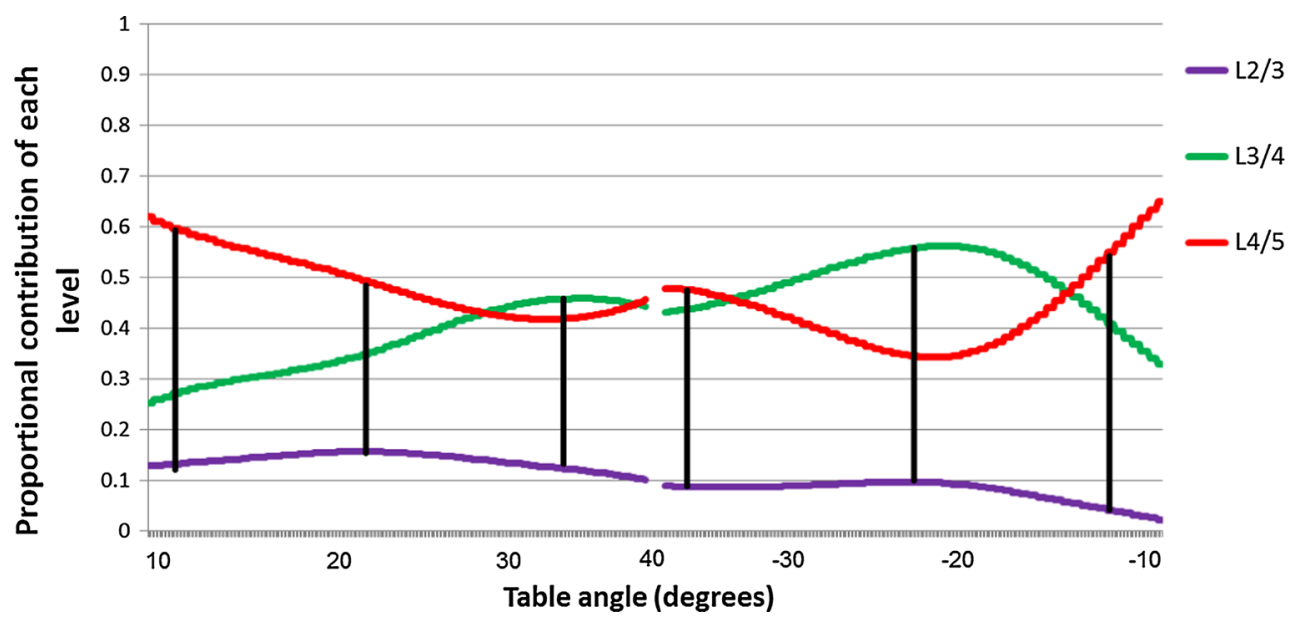

Fig. 3 Measurement of variability of proportional inter-vertebral ranges. Patterns of proportional inter-vertebral rotation from a patient who is flexing passively. The range was calculated for each data point (X-axis) to obtain the variance for that direction (black lines).
Proportional range variances $(P R V)$ for each direction were summed to give the combined proportional range variance $(C P R V)$. $(\mathrm{CPRV}=$ PRV flexion + PRV extension + PRV left + PRV right $)$
Table 2 Participant demographics

\begin{tabular}{lll}
\hline Variable & Mean (SD) \\
\cline { 2 - 3 } & Patients & Controls \\
\hline$N$ & 40 & 40 \\
Age & $35.9(8.6)($ range 21-50) & $35.7(8.4)($ range 21-50) \\
Gender (\% M) & $55 \%(n=22)$ & $55 \%(n=22)$ \\
BMI & $24.5(2.6)($ range 19.8-29.3) & $24.5(2.8)($ range 19.5-31.5) \\
Average 6-month intensity & $5.9(1.73)($ range 3-10) & - \\
$\quad$ von Korff)/10 & $8.3(1.22)($ range 5-10) & - \\
$\quad \begin{array}{l}\text { Worst possible pain in the } \\
\text { past 6 months (von Korff)/10 }\end{array}$ & $4.1(2.05)($ range 0-8) & - \\
Current pain intensity (von Korff)/10 & $7.8(4.1)($ range 4-19) & - \\
Disability (RMDQ)/24 &
\end{tabular}

range). The variance of these ranges was computed and expressed as PRV (Fig. 3). This was used to measure the fluctuations in the proportional contributions between the three levels. The PRVs for all four directions were tested for co-dependency and then summed to obtain a CPRV for each participant.

Statistical analysis of the maximum RoM utilised Stats Direct (V2.7.8) and SPSS (V21 IBM software) to calculate ICC and SEM. Additionally, to find out if the maximum range for any level or direction was different in patients and controls undergoing controlled passive motion, twoway unpaired t tests were used. As the PRV and CPRV data were not normally distributed, their distributions were compared using a two-tailed Mann-Whitney $U$-test. The sensitivity and specificity of the PRVs and CPRV to discriminate cohorts was then determined by receiver operating characteristic (ROC) curve analysis (extended trapezoidal rule method). CPRV was correlated to pain and disability in the patient group.

\section{Results}

\section{Participants}

Forty-two consenting patients with a diagnosis of chronic non-specific mechanical low back pain were recruited: five were from private chiropractic clinics, one from an outpatient physiotherapy department and 34 from a chiropractic college teaching clinic. Two patients underwent fluoroscopy but had unusable data due to poor image quality. One hundred and forty-six healthy volunteers agreed to submit their personal details to a database. Forty of these were matched for gender, age and BMI.

The mean effective radiation dose for all participants was $0.561 \mathrm{mSv}$ (SD 0.154). Participant demographics are described in Table 2 and the maximum inter-vertebral rotations (SD) achieved from the controlled passive protocol in Table 3 . The only significant difference between patients and controls was for maximum IV-RoM in L4/5 left side bending. 
Table 3 Maximum IV rotations for patients and controls

\begin{tabular}{llll}
\hline $\begin{array}{l}\text { Direction and } \\
\text { inter-vertebral } \\
\text { level }\end{array}$ & $\begin{array}{l}\text { Maximum rotational } \\
\text { value }\left(^{\circ}\right) \text { mean }(\mathrm{SD}) \\
\text { patients }\end{array}$ & $\begin{array}{l}\text { Maximum rotational } \\
\text { value }\left({ }^{\circ}\right) \text { Mean }(\mathrm{SD}) \\
\text { controls }\end{array}$ & $p^{*}$ \\
\hline Left L2/3 & $6.74(1.53)$ & $6.80(1.74)$ & 0.87 \\
Left L3/4 & $7.13(2.00)$ & $6.92(1.51)$ & 0.59 \\
Left L4/5 & $5.62(2.63)$ & $6.82(2.19)$ & 0.03 \\
Right L2/3 & $5.94(1.48)$ & $5.72(1.59)$ & 0.52 \\
Right L3/4 & $6.68(2.01)$ & $5.96(1.32)$ & 0.06 \\
Right L4/5 & $5.81(2.80)$ & $6.44(1.92)$ & 0.25 \\
Flex L2/3 & $4.23(1.56)$ & $4.05(1.54)$ & 0.61 \\
Flex L3/4 & $5.89(1.70)$ & $5.49(1.75)$ & 0.30 \\
Flex L4/5 & $7.10(2.46)$ & $6.46(1.51)$ & 0.17 \\
Ext L2/3 & $5.04(1.98)$ & $4.64(1.90)$ & 0.36 \\
Ext L3/4 & $4.15(1.67)$ & $4.11(1.53)$ & 0.92 \\
Ext L4/5 & $4.78(2.43)$ & $5.31(2.37)$ & 0.32 \\
\hline
\end{tabular}

* Students $t$ test

Repeatability

Inter- and intra-observer reliability and agreement for maximum rotations were high (Table 4). The highest ICC was for right intra observer at $\mathrm{L} 4 / 5$ (ICC $=0.998,95 \% \mathrm{CI}$ 0.992-0.999) and the lowest SEM was 0.081 for right intra observer at $\mathrm{L} 2 / 3$. The lowest ICC was for inter-observer extension at $\mathrm{L} 3 / 4(\mathrm{ICC}=0.737,95 \%$ CI $0.228-0.928)$ and the highest SEM was for inter-observer extension at L2/3 (SEM = 0.772). Repeatability was excellent for levels and directions combined, the mean inter- and intraobserver ICCs being 0.956 (95\% CI 0.837-0.989) and $0.990(0.981-0.999)$ and the SEM's $0.15^{\circ}$ and $0.07^{\circ}$, respectively.

Variance in ranges between proportional motion patterns

The sensitivity and specificity of PRVs and the CPRV for patients are shown in Table 5. There were no significant differences in PRVs, but the median CPRV value for patients (0.011) was significantly higher than for controls (0.008) ( $p=0.008$, two-sided Mann-Whitney).

The number of patients and controls whose CPRV levels fell above the ROC analysis cut-off value in patients and controls were 31/40 (78 \%) and 18/40 (45\%), respectively (Yates-corrected $\chi^{2}=7.584, p=0.006$ ). The sensitivity and specificity of CPRV for discriminating patients from controls were $0.775 \quad(0.615-0.891)$ and 0.550 $(0.385-0.707)$. This indicates the possibility of a biomechanical subgroup within the patient population.

Correlation of CPRV with patient characteristics

There were no significant correlations (Kendall's tau) between CPRV and the patient characteristics: age $(t=0.215, p=0.0 .056)$, BMI $(t=0.046, p=0.683)$, gender (Fisher exact, two-sided $p=0.901$ ), disability scores (RMDQ) $(t=0.155, \quad p=0.181)$ and three

Table 4 Inter- and intra-observer reliability (ICCs 2, 1 absolute) and agreement (SEM agreement) for maximum RoM for each level and direction ( $n=10$ per direction)

\begin{tabular}{|c|c|c|c|c|c|c|}
\hline & \multicolumn{3}{|l|}{ Inter-observer } & \multicolumn{3}{|l|}{ Intra-observer } \\
\hline & $\mathrm{L} 2 / 3$ & $\mathrm{~L} 3 / 4$ & $\mathrm{~L} 4 / 5$ & $\mathrm{~L} 2 / 3$ & $\mathrm{~L} 3 / 4$ & $\mathrm{~L} 4 / 5$ \\
\hline \multicolumn{7}{|l|}{ Left } \\
\hline SEM $\left(^{\circ}\right)$ & 0.459 & 0.276 & 0.261 & 0.172 & 0.158 & 0.147 \\
\hline ICC & 0.862 & 0.971 & 0.990 & 0.987 & 0.993 & 0.997 \\
\hline $95 \% \mathrm{CI}$ & $(0.561-0.963)$ & $(0.895-0.993)$ & $(0.960-0.997)$ & (0.949-0.997) & $(0.971-0.998)$ & $(0.989-0.999)$ \\
\hline \multicolumn{7}{|l|}{ Right } \\
\hline SEM $\left(^{\circ}\right)$ & 0.553 & 0.176 & 0.197 & 0.081 & 0.106 & 0.123 \\
\hline ICC & 0.853 & 0.971 & 0.992 & 0.997 & 0.987 & 0.998 \\
\hline $95 \% \mathrm{CI}$ & $(0.512-0.961)$ & $(0.892-0.993)$ & $(0.960-0.998)$ & $(0.988-0.999)$ & $(0.945-0.997)$ & $(0.992-0.999)$ \\
\hline \multicolumn{7}{|l|}{ Flexion } \\
\hline $\operatorname{SEM}\left({ }^{\circ}\right)$ & 0.309 & 0.165 & 0.312 & 0.127 & 0.125 & 0.101 \\
\hline ICC & 0.912 & 0.975 & 0.967 & 0.975 & 0.981 & 0.997 \\
\hline $95 \% \mathrm{CI}$ & $(0.685-0.978)$ & $(0.905-0.994)$ & $(0.877-0.992)$ & $(0.862-0.994)$ & $(0.904-0.996)$ & $(0.987-0.999)$ \\
\hline \multicolumn{7}{|l|}{ Extension } \\
\hline SEM $\left(^{\circ}\right)$ & 0.772 & 0.406 & 0.265 & 0.347 & 0.244 & 0.194 \\
\hline ICC & 0.761 & 0.737 & 0.988 & 0.959 & 0.920 & 0.993 \\
\hline $95 \%$ CI & $(0.273-0.935)$ & $(0.228-0.928)$ & $(0.955-0.997)$ & $(0.849-0.990)$ & (0.719-0.979) & (0.973-0.998) \\
\hline
\end{tabular}


Table 5 Discrimination between patients and controls by proportional range variance (PRV): sensitivity, specificity and likelihood ratios of PRV for each direction and combined (CPRV) and statistical significance between groups

\begin{tabular}{llllllll}
\hline Variable & Sensitivity & Specificity & AUC & Cutoff & +ve LR & -ve LR \\
\hline PRV left & $0.675(0.509-0.814)$ & $0.550(0.385-0.707)$ & 0.579 & 0.00074 & $1.500(1.014-2.297)$ & $0.591(0.343-0.983)$ & 0.222 \\
PRV right & $0.775(0.615-0.892)$ & $0.500(0.338-0.662)$ & 0.610 & 0.00105 & $1.550(1.108-2.266)$ & $0.450(0.231-0.838)$ & 0.090 \\
PRV flexion & $0.850(0.702-0.943)$ & $0.300(0.166-0.485)$ & 0.568 & 0.00106 & $1.214(0.956-1.591)$ & $0.500(0.210-1.154)$ & 0.294 \\
PRV extension & $0.825(0.672-0.927)$ & $0.450(0.293-0.615)$ & 0.623 & 0.00180 & $1.500(1.113-2.118)$ & $0.389(0.182-0.794)$ & 0.059 \\
Combined $(C P R V)^{\mathrm{a}}$ & $0.775(0.615-0.892)$ & $0.550(0.385-0.707)$ & 0.672 & 0.00865 & $1.722(1.203-2.593)$ & $0.409(0.213-0.749)$ & 0.008 \\
\hline
\end{tabular}

Median CPRV values: patients $=0.011$, controls $=0.008(p=0.008$ Mann-Whitney $)$

* Mann-Whitney, two-sided $p$

${ }^{\mathrm{a}} \mathrm{CPRV}=\mathrm{PRV}$ left + PRV right + PRV flexion + PRV extension

dimensions from the von Korff Chronic Pain Grade. These were based on ten-point visual analogue scales for current pain intensity $(t=-0.201, p=0.086)$, pain intensity over the past 6 months $(t=0.207, p=0.067)$ and worst pain experienced in the past 6 months $(t=-0.045, p=0.706)$.

\section{Discussion}

Many excellent studies have addressed in vivo spinal kinematic analysis using advanced imaging technologies. Devices such as bi-planar fluoroscopy [30, 31] and upright, kinetic MRI [32-34] have been used to provide 3D information about the relationships between inter-vertebral RoM and structural changes. Such 3-D systems have the added advantage of being able to measure axial rotation as well as rotations and translation in other planes [30]. However, these are mainly research systems whose use is not easily translated into practice and whose results are usually reported as 2-D end-of-range measures. They do not generally analyse continuous motion patterns. QF systems, by contrast, have received US Food and Drug Agency clearance for roles that are traditionally filled by flexion-extension radiographs. They require only motion tables to run with existing hospital C-arm fluoroscopy units to output quantifiable rotation, translation, ICR and attainment rates in two planes and in both active and passive motion. Additionally, the calculated radiation dose is less than standard lumbar spine radiographs [35] which makes it suitable for clinical use.

This study updated the inter- and intra-observer repeatability of maximum inter-vertebral rotation range [26] resulting from improvements in the QF technology and demonstrated a significant difference in maximum rotation between controls and patients for one level and direction only. Additionally, the study used a new measure of combined continuous proportional motion (PRV/CPRV) to compare patients and controls and to determine sensitivity and specificity for mechanical low back pain. The results suggest that combined variances of proportional patterns in patients were not as regular or evenly proportioned as those in controls, suggesting an association between CPRV and CNSLBP and supporting the conclusions of previous studies $[15,20]$. The fact that little difference was found in respect of raw IV-RoM (Table 3), despite standardisation of table range, reflects the variable contributions by the segments from L2 -5 . In this study, L2-5 absorbed between 35 and $51 \%$ of this motion-a source of extraneous variability that was avoided by calculating proportional motion as recommended by a previous International Forum [18].

Using PRV in continuous sequences and combining them to obtain a summary variable CPRV is a new concept that focuses on fluctuations in motion patterns within and between levels (Fig. 1). This addresses subgrouping in terms of movement dysfunction and may reflect pathoanatomical changes in passive components such as discs and ligaments. Such changes may include scarring, dehydration, glycation, calcification, fissuring and annular tears [11]. However, back pain is unlikely to exist to the exclusion of other biological factors, such as chemical pain stimuli, central sensitisation and abnormal muscle recruitment patterns during active motion.

No significant associations were found between CPRV and the patient characteristics: age, gender, BMI, disability, and pain, which are consistent with Abbott et al. [15]; however, this study examined a primary care population with low levels of pain and disability.

\section{Limitations}

The sensitivity and specificity of the CPRV and its AUC supports the existence of a subgroup based on biomechanics, but it is not intended to constitute a diagnostic test. Additionally, proportional ranges cannot be used to determine hyper- or hypo-mobility because they cannot be related back to rotational values. 
Finally, our study only analysed patients at the lower end of the pain severity scale. Studies of more disabled patients, such as those with spondylolisthesis, spinal stenosis, instability or electing for, or having had spinal surgery, may show greater differences. Additionally, only rotation was examined; however, the inclusion of other kinematic variables such as translation, instantaneous axis of rotation and attainment rate may also improve discrimination and are suggested for further research in this area. Recording during weight bearing motion would help to give a more complete picture of the relationship between inter-vertebral movement and persistent back pain if the added complexity of loading and muscle contraction can be controlled for.

\section{Conclusion}

The variation in proportional motion between lumbar vertebrae during passive, recumbent motion was greater in patients with CNSLPB than in matched healthy controls, indicating that biomechanical factors in passive structures play a part. Additional studies with this method should be useful for improving our understanding of the pathophysiology of non-specific low back pain and the relationship of this to treatment outcomes. These would include replication of the present findings in other participant groups, the incorporation of additional kinematic variables, studies of patient subgroups (e.g. instability, post-surgical disability, etc.) and the possible prediction of future back pain disability, including risk of chronicity and poor outcome.

Acknowledgments Funding for this study was received from the National Institute for Health Research under the Clinical Academic Training Doctoral Research Fellowship scheme. This report/article presents independent research. The views expressed in this publication are those of the author(s) and not necessarily those of the NHS, the NIHR or the Department of Health. The authors wish to acknowledge the contributions of the participants, of Linda Bruce for her help with recruitment and Alex Breen for software development and support.

\section{Conflict of interest None.}

Open Access This article is distributed under the terms of the Creative Commons Attribution License which permits any use, distribution, and reproduction in any medium, provided the original author(s) and the source are credited.

\section{References}

1. Murray CJL, Vos T, Lazano R, Naghavi M, Flaxman AD, Michaud C (2012) Disability-adjusted life years (DALYs) for 291 diseases and injuries in 21 regions, 1990-2010: a systematic analysis for the Global Burden of Disease Study 2010. Lancet 380:2197-2223
2. Deyo RA, Rainville J, Kent DL (1992) What can the history and physical examination tell us about low back pain? JAMA 268:760-765

3. Waddell G (1998) The back pain revolution. Churchill Livingstone, Edinburgh

4. Mannion AF, Dolan P, Adams MA (1996) Psychological questionnaires: do "abnormal" scores precede or follow first-time low back pain? Spine 21:2603-2611

5. Adams MA, Mannion AF, Dolan P (1999) Personal risk factors for first-time low back pain. Spine 24:2497-2505

6. Chou R, Shekelle P (2010) Will this patient develop persistent, disabling low back pain? JAMA 303(13):1295-1302

7. Kent PM, Keating JL (2008) Can we predict poor recovery from recent-onset nonspecific low back pain? A systematic review. Man Ther 13:12-28

8. Leone A, Guglielmi G, Cassar-Pullicino VN, Bonomo L (2007) Lumbar intervertebral instability: a review. Radiology 245:62-77

9. Nizard RS, Wybier M, Laredo JD (2001) Radiologic assessment of lumbar intervertebral instability and degenerative spondylolisthesis. Radiol Clin North Am 39:55-71

10. Yeager MS, Cook DJ, Cheng BC (2014) Reliability of computerassisted lumbar intervertebral measurements using a novel vertebral motion analysis system. Spine J 14:274-281

11. Karayannis NV, Jull GA, Hodges PW (2012) Physiotherapy movement based classification approaches to low back pain: comparison of subgroups through review and developer/expert survey. BMC Musculoskelet Disord 13:24

12. Laird RA, Kent P, Keating JL (2012) Modifying patterns of movement in people with low back pain-does it help? A systematic review. BMC Musculoskelet Disord 13:169

13. Taghipour-Darzi M, Takamjani EE, Salavati M, Mobini B, Zekavat $H$ (2012) The validity of vertebral translation and rotation in differentiating patients with lumbar segmental instability. Physiother Res Int 17:227-234

14. Deitz AK, Mellor FE, Teyhan DS, Panjabi MM, Wong KWM (2010) Kinematics of the aging spine: a review of past knowledge and survery of recent developments, with a focus on patientmanagement implications for the clinical practitioner. In: Yue Jl, Guyer RD, Johnson PJ, Khoo LT, Hochschuler SH (eds) The comprehensive treatment of the aging spine: minimally invasive and advanced techniques. Elsevier, Philadelphia

15. Abbott J, Fritz J, McCane B, Shultz B, Herbison P, Lyons B, Stefanko G, Walsh R (2006) Lumbar segmental mobility disorders: comparison of two methods of defining abnormal displacement kinematics in a cohort of patients with non-specific mechanical low back pain. BMC Musculoskelet Disord 7:45

16. Teyhen DS, Flynn TW, Bovik AC, Abraham LD (2005) A new technique for digital fluoroscopic video assessment of sagittal plane lumbar spine motion. Spine 30:E406-E413

17. White AA, Panjabi MM (1990) Clinical biomechanics of the spine. JB Lippincott, Philadelphia

18. Breen AC, Teyhen DS, Mellor FE, Breen AC, Wong K, Deitz A (2012) Measurement of inter-vertebral motion using quantitative fluoroscopy: Report of an international forum and proposal for use in the assessment of degenerative disc disease in the lumbar spine. Adv Orthop 2012:1-10

19. Ahmadi A, Maroufi N, Behtash H, Zekavat H, Parnianpour M (2009) Kinematic analysis of dynamic lumbar motion in patients with lumbar segmental instability using digital videofluoroscopy. Eur Spine J 18:1677-1685

20. Teyhen DS, Flynn TW, Childs JD, Kuklo TR, Rosner MK, Polly DW, Abraham LD (2007) Fluoroscopic video to identify aberrant lumbar motion. Spine 32:E220-E229

21. Mellor FE, Muggleton JM, Bagust J, Mason WMA, Thomas PW, Breen AC (2009) Midlumbar lateral flexion stability measured in healthy volunteers by in vivo fluoroscopy. Spine 34:E811-E817 
22. Wong KWN, Leong JCY, Chan M-K, Lu WW (2004) The flexion-extension profile of lumbar spine in 100 healthy volunteers. Spine 29:1636-1641

23. Taghipour-Darzi M, Ebrahimi-Takamjani E, Salavati M, Mobini B, Zekavat H (2009) Reliability of quality measures of movement in lumbar spine flexion-extension radiography. J Back Musculoskelet Rehabil 22:149-156

24. Roland M, Morris R (1983) A study of the natural history of back pain: part I-development of a reliable and sensitive measure of disability in low back pain (1982 Volvo Award in Clinical Science). Spine 8:141-150

25. Von Korff M, Ormel J, Keefe FJ, Dworkin SF (1992) Grading the severity of chronic pain. Pain 50:133-149

26. Breen A, Muggleton J, Mellor F (2006) An objective spinal motion imaging assessment (OSMIA): reliability, accuracy and exposure data. BMC Musculoskelet Disord 7:1-10

27. Frobin F, Brinckmann P, Lievseth G, Biggemann M, Reikeras O (1996) Precision measurement of segmental motion from flexionextension radiographs of the lumbar spine. Clin Biomech 11:457-465

28. Shrout PE, Fleiss JL (1979) Intraclass correlations: uses in assessing rater reliability. Psychol Bull 86:420-428

29. de Vet HCW, Terwee CB, Knol DL, Bouter LM (2006) When to use agreement versus reliability measures. J Clin Epidemiol 59:1033-1039
30. Li G, Wang S, Passias P, Xia Q, Li G, Wood K (2009) Segmental in vivo vertebral motion during functional human lumbar spine activities. Eur Spine J 18:1013-1021

31. Yao Q, Wang S, Shin JH, Li G, Wood KB (2012) Lumbar facet joint motion in patients with degenerative spondylolisthesis. J Spinal Disord Tech 26:E19-E27

32. Alyas F, Connell D, Saifuddin A (2008) Upright positional MRI of the lumbar spine. Clin Radiol 63:1035-1048

33. Kulig K, Powers C, Landel R, Chen H, Fredericson M, Guillet M, Butts K (2007) Segmental lumbar mobility in individuals with low back pain: in vivo assessment during manual and self-imposed motion using dynamic MRI. BMC Musculoskelet Disord 8:8

34. Miyazaki M, Hong SW, Yoon SH, Zou J, Tow B, Alanay A, Abitbol J, Wang J (2008) Kinematic analysis of the relationship between the grade of disc degeneration and motion unit of the cervical spine. Spine 33:187-193

35. UNSCEAR (2010) Sources and effects of ionising radiation. Report to the general assembly with scientific annexes. In: United Nations Scientific Committee on the Effects of Atomic Radiation (ed) Medical radiation exposures Annex A 2008. United Nations 